\title{
Phylogenetic diversity of plants alters the effect of species richness on invertebrate herbivory
}

Long-standing ecological theory proposes that diverse communities of plants should experience a decrease in herbivory. Yet previous empirical examinations of this hypothesis have revealed that plant species richness increases herbivory in just as many systems as it decreases it. In this study, I ask whether more insight into the role of plant diversity in promoting or suppressing herbivory can be gained by incorporating information about the evolutionary history of species in a community. In an old field system in southern Ontario, I surveyed communities of plants and measured levels of leaf damage on 27 species in 38 plots. I calculated a measure of phylogenetic diversity (PSE) that encapsulates information about the amount of evolutionary history represented in each of the plots and looked for a relationship between levels of herbivory and both species richness and phylogenetic diversity using a generalized linear mixed model (GLMM) that could account for variation in herbivory levels between species. I found that species richness was positively associated with herbivore damage at the plot-level, in keeping with the results from several other recent studies on this question. On the other hand, phylogenetic diversity was associated with decreased herbivory. Importantly, there was also an interaction between species richness and phylogenetic diversity, such that plots with the highest levels of herbivory were plots which had many species but only if those species tended to be closely related to one another. I propose that these results are the consequence of interactions with herbivores whose diets are phylogenetically specialized (for which I introduce the term cladophage), and how phylogenetic diversity may alter their realized host ranges. These results suggest that incorporating a phylogenetic perspective can add valuable additional insight into the role of plant diversity in explaining or predicting levels of herbivory at a whole-community scale. 


\section{Title Page}

2

3 Authors:

4

5 Russell Dinnage

6

\section{Affiliations:}

1. CSIRO

Ecosystem Sciences

Floreat, WA

Australia

2. University of Western Australia

School of Animal Biology

Perth, WA

Australia

3. University of Toronto

Department of Ecology and Evolutionary Biology

Toronto, Ontario

Canada

\section{Corresponding Author:}

Russell Dinnage

Address: Private Bag 5, Wembley, WA 6193, Australia

Phone: +61893336126

Email: russell.dinnage@csiro.au

31

32 


\section{Introduction}

The insect herbivore flies, crawls, hovers, and feeds in a matrix of stems, roots, flowers and leaves. Thousands do this in a typical community of plants in what - to us - is an impenetrably complex tangle of traits, each the product of millions of years of evolution. How then are we to understand the aggregate patterns that emerge from such a community? Indeed, community ecologists have long struggled to understand how the identity and traits of individual plant species add together and interact to determine herbivore communities and the damage they cause.

Though much work on insect herbivory has focused on interactions between single pairs of insect and plant species, it is also important to understand the phenomenon at the level of whole plant communities. After all, many of the consequences of major ecosystem changes will be manifest at the level of the community, and one-to-one interactions may not always be additive (Agrawal, Lau, \& Hamback 2006; Agrawal et al. 2007).

One way of understanding herbivory at the community level is to look at the effects of plant species richness. Plant species richness is one of the simplest way to summarize information about many species at the community level, and studies of its role in herbivory link up nicely with the body of literature on the relationship between diversity and ecosystem functioning (Siemann et al. 1998; Haddad et al. 2001; Loreau et al. 2001; Hooper et al. 2005; Cardinale et al. 2006; Balvanera et al. 2006; Cardinale et al. 2007; Scherber et al. 2010a). Insect herbivore damage is a useful reflection of the activities of insect herbivores in plant communities, as well as a phenomenon of interest in and of itself, with implications for the health of a plant community.

There are some clear theoretical predictions about the effects of plant species richness on herbivory, which derive from a simple understanding of direct trophic interactions between plants and insects. Root (1973) suggested that increased plant species richness should lead to a decrease in specialist herbivores, and thus to a decrease in herbivory. The

Resource Concentration Hypothesis states that if the number of plant species in a patch is higher, the density of each plant species must be lower, and so specialist herbivores of those 1 species will be less likely to find such a patch, stay in such a patch, and do damage in such a patch. On the other hand, the presence of a wide variety of plant species provides a wide variety of nutritional resources for generalist herbivores, which may prefer to eat in diverse patches, and may thrive more in them too (Unsicker et al. 2008; Schuldt \& Baruffol 2010). I will refer to this idea as the Dietary Mixing Hypothesis (after Bernays et al. 1994). 
67 of these two hypotheses applies more widely to plant-herbivore systems, because whether

68 plant species richness has a positive, negative, or no relationship with herbivory depends on

69 the system under study. A review of the literature shows that there are roughly equal numbers

70 of studies showing that plant diversity has a positive effect on herbivory as there are showing

71 a negative effect, at least for studies that looked at the effect of species richness on the

72 magnitude of herbivory (Table 1). This suggests that the role of plant species richness may

73 sensitively depend on aspects of either the plant or the herbivore community. Based on the

74 Resource Concentration Hypothesis and the Dietary Mixing Hypothesis described above, the

75 relative abundance of generalist vs. specialist herbivores likely plays a role. For example, Lau

76 et al. (2008) were able to separate damage done by specialists and damage done by

77 generalists on Lespedeza capita planted in low and high diversity plots. They found that

78 damage by generalists increased with high plant diversity and that damage from specialists

79 decreased with high plant diversity, in accordance with the predictions of the Dietary Mixing

80 hypothesis and the Resource Concentration Hypothesis, respectively.

Species richness is only a coarse measure of the diversity and structure of a community, and so including other sources of information about communities may help to clarify such simple predictions. Attempts to include more of the natural complexity of plant communities to understand community herbivory include using functional diversity in addition to plant species richness (Siemann et al. 1998; Koricheva et al. 2000;

86 Prieur-Richard, Lavorel, \& Linhart 2002; Scherber et al. 2006, 2010b) reducing species

87 composition to low dimensional quantitative measures using ordination (Koricheva et al.

88 2000; Pfisterer, Diemer, \& Schmid 2003; Schaffers et al. 2008), and incorporating information about plant species' evolutionary history, using community phylogenetics. Here, I explore the use of community phylogenetics to understand insect herbivory at the plant community level.

93 development of sophisticated ways of incorporating this information into diversity measures

94 (Helmus et al. 2007; Cavender-Bares et al. 2009; Vamosi et al. 2009; Cadotte et al. 2010;

95 Pausas \& Verdú 2010), is opening a new avenue of exploration for understanding the effects

96 of plants on ecosystem function at the whole community scale. For example, recent analyses

97 have shown that various measures of phylogenetic diversity are associated with the

98 productivity of plant communities (Cadotte, Cardinale, \& Oakley 2008; Cadotte et al. 2009;

99 Connolly et al. 2011; Flynn et al. 2011) and the insect assemblages associated with them 
101 about herbivory can provide a useful framework for predicting when species richness may

increase or decrease herbivory in plant communities.

Phylogenetic diversity may be particularly important to herbivores and herbivory because of the widespread occurrence of herbivores with phylogenetically restricted diets they feed on a group of closely related species (Ehrlich \& Raven 1964; Janzen 1980; Ødegaard, Diserud, \& Østbye 2005; Weiblen et al. 2006; Gossner et al. 2009; Futuyma \& Agrawal 2009). I will refer to these species as cladophages, from the greek klados for 'branch', and the greek phagein for 'to eat' - thus 'branch-eater', or an organism that feeds preferentially on just one of the branches of the tree of life that is available to them. The act of feeding in this manner can be called cladophagy. Ultimately, because many plant traits are conserved through evolutionary time, phylogeny will often be a reasonable proxy for phenotypic divergence - and thus phylogenetic diversity a reasonable proxy for phenotypic diversity (Cavendar-Bares et al. 2009). Since herbivores are presumed to feed on phenotypically similar plant species more often than not, phylogenetic diversity will indirectly effect how herbivores interact with plant communities.

In this study I asked whether the phylogenetic diversity of old-field plant communities can predict the amount of herbivore damage on plants at a community-scale.

\section{Materials and methods}

\section{Data collection}

The study was conducted at the Koffler Scientific Reserve (KSR) at Joker's Hill (King City, Ontario, Canada; http://www.ksr.utoronto.ca/jh.html), a 350 hectare property containing a mix of primary forest, secondary forest and open habitats, including a large area of old field sites. I was granted permission by the site director - Ann Zimmerman - to conduct the research there.

\section{Species survey}

I haphazardly selected 3810 x 10 meter plots spread across the available old field habitat at KSR. In early August, I surveyed each plot within 4 randomly placed 1x1 meter quadrats, one in each of the four quadrants of the larger plot. I noted the presence or absence of each forb species within the quadrats and combined the data from all four quadrats into a low resolution measure of abundance (ranging from 0-4) for each species within each 10x10 meter plot. I decided to focus on forbs to the exclusion of grasses for several reasons. 
135 There were only two common species of grass, which occurred in nearly every one of the

plots surveyed, and so inclusion of grasses in the phylogenetic diversity measures would have only diluted the signal from the forbs. I hypothesized that phylogenetic diversity amongst forbs would be the most important to understanding herbivory on forbs. This is because grasses and forbs share few herbivores, except for the most generalist. As an example, Dinnage et al. (2012) showed that the largest difference in arthropod communities collected from different prairie plant species was between grasses and forbs.

Using this data, I calculated the species richness and abundance-weighted phylogenetic diversity for all 38 plots. This data, along with the species composition of all 38 plots, can be found in Table S1 in Supporting Information.

\section{Herbivory survey}

In order to quantify the amount of herbivore damage in the plots, I selected 27 of the most common species at KSR to measure damage (Fig. 1). These species acted as phytometers to capture the overall herbivore pressure in the plot. In late August - over a period of approximately two weeks - I measured herbivore damage rates in the 38 plots. For each of the phytometer species that occured in a given plot, I sampled 10 individual plants by counting the number of damaged leaves and the number of total leaves on each one. The dataset then consisted of 1862 datapoints, each from an individual plant.

I chose this set of phytometer species before the commencement of the study, based on my personal knowledge of which species seemed to make up the most apparent membership of the old field communities (i.e. the 'overstory'). This intuition seems justified, because of the 25 species which were surveyed in the plots, but for which I did not measure damage, 17 were found in only 1 or 2 plots ( $<5 \%$ of total plots), and 24 were found in 5 or fewer plots ( $<13 \%$ of total plots). It is unlikely that measurements of herbivory on these species could have changed the results presented here substantially, unless rare species systematically differed in their response to plant diversity. The one exception to this general pattern was Taraxacum officianale, which was found in 16 plots and was not measured for herbivory. However, T. officianale is an understory plant, which remains as a rosette for most of its life history. It only produces a few leaves (4-10), all of which usually sustain some herbivore damage (personal observation). Given this lack of variation in herbivory within $T$. offianale under the method of measurement that I chose, it would be unlikely to affect the results substantially (because if there is no variation, then it cannot vary with plant diversity 
169

170

171

172

173

174

Supplementary Table S1.

\section{Phylogeny and diversity indices}

I created a phylogenetic tree containing all the most common old field species found at my site using methods previously described (Dinnage 2009). I then pruned the tree so that the remaining species matched those found in the plots used for this study (Fig. 1).

Using this phylogeny I calculated an index of abundance-weighted phylogenetic diversity for each plot. There are several such indices available - I chose Phylogenetic Species Evenness (PSE; Helmus et al. 2007). PSE measures the amount of evolutionary history represented in a community by calculating the expected variance in a hypothetical continuous trait modeled as evolving through Brownian motion across the community phylogeny, and is standardized by the expected variance of the same modeled trait on a star phylogeny - where phylogenetic distances among all species are equal. This captures one of the fundamental features of interest in phylogenetic diversity, that it may encapsulate information about the ecological similarity of species in a community. I chose PSE for this reason, and because it is theoretically (and empirically in this study) independent of species richness. Thus, by using it, I could evaluate the independent contributions of species richness and phylogenetic diversity without the problems of co-linearity and heteroscedasticity common to many other phylogenetic diversity indices (e.g. Schweiger et al. 2008; Pio et al. 2011). PSE ranges between 0 and 1, where high values are associated with high phylogenetic diversity. Low values are associated with low phylogenetic diversity, or phylogenetic clustering - small average phylogenetic distances among species in the community. It is possible that I could have seen different results with a different metric, but PSE is highly correlated with a number of other metrics (Cadotte et al. 2010), and so the results presented here should at least apply to this general 'class' of phylogenetic diversity indices.

I used species richness rather than an abundance-weighted measure because I was interested in the effects of adding or subtracting species. This combined with the phylogenetic diversity measure can give a statistical measure of adding species of different phylogenetic distances from the species already present. In addition, abundance weighting is easily interpretable for a measure like phylogenetic diversity, because in essence it is a weighted average, and phylogeny is made from continuous measures of branch length. On the other hand, abundance weighted measures like the Shannon-Weaver index are abstracted quantities with no simple interpretation biologically (e.g. Goodman 1975; Austin 1999). I did 
the phylogenetic diversity measure, though abundance-weighted, was not confounded with species evenness. In addition, evenness was not a significant predictor of herbivory when included as a factor in the model described below, and so I did not use it.

\section{Statistical analysis}

In order to account for variation in species composition across plots, I used a generalized linear mixed model (GLMM) with crossed random effects, to disentangle species and plot-level effects on herbivory. The number of damaged leaves on a plant can be modelled as a binomial distribution, with a damaged leaf considered a Bernoulli success (for the herbivores) and an undamaged leaf a failure. Factors that may influence the probability of a leaf being damaged were incorporated into the model with a logit link.

I used a logit-normal-binomial statistical model to analyze the data, as follows:

$$
\begin{gathered}
\operatorname{Damaged}_{i} \sim \operatorname{Binomial}\left(p_{i}, N_{i}\right) \\
\operatorname{Logit}\left(p_{i}\right)=\alpha+\mu_{\text {species }[i]}^{1}+\mu_{\text {plot }[i]}^{2}+\mu_{\text {obs }[i]}^{3}+\beta_{p d} P D_{\text {plot }[i]}+\beta_{\text {sr }} S R_{p l o t[i]}+\beta_{p d^{*} r}\left(P D^{*} S R\right)_{p l o t[i]} \\
+\beta_{\text {date }} D A T E_{\text {plot }[i]} \\
\mu_{\text {species }[i]}^{1} \sim \operatorname{Normal}\left(0, \sigma_{\text {species }}^{2}\right), \mu_{\text {plot }[i]}^{2} \sim \operatorname{Normal}\left(0, \sigma_{\text {plot }}^{2}\right), \mu_{\text {obs }[i]}^{3} \sim \operatorname{Normal}\left(0, \sigma_{\text {obs }}^{2}\right)
\end{gathered}
$$

Where Damaged $_{i}$ is the number of damaged leaves on individual plant $i, p_{i}$ is the probability of any given leaf on plant $i$ being damaged, and $N_{i}$ is the total number of leaves on plant $i$. $\mathrm{PD}_{\text {plot }[i]}$ and $\mathrm{SR}_{\text {plot }[i]}$ are the phylogenetic diversity and the species richness, respectively, for the plot in which plant $i$ was found. DATE $E_{\text {plot }[i]}$ is the date on which I sampled the plot, to control for any increases in herbivory that may have occurred while the sampling was ongoing. $\mu_{\text {species[i] }}^{1}$ and $\mu_{\text {plot [i] }}^{2}$ are the random effects for species and plot, respectively. $\mu_{\text {obs[i] }}^{3}$ is a random effect for the individual observation which was included to account for any over- or under-dispersion in the data since the binomial distribution contains no variance parameter. The $\alpha$ (intercept) and $\beta$ parameters are the fixed effects.

I used the lme4 package (Bates, Maechler, \& Bolker 2011) for R statistical environment (R Development Core Team 2010) to fit the model.

Plot level herbivory (after accounting for species-level variation, sampling date, and observation) can then be estimated as the best linear unbiased predictors (BLUPs) sometimes referred to as the conditional modes - of $p_{i}$ (hereafter estimated proportional leaf damage). For plot $j$, this is equal to $p_{j}=\operatorname{Logit}^{-1}\left(\alpha+\mu^{2}{ }_{j}+\beta_{p d} P D_{j}+\beta_{s r} S R_{j}+\beta_{p d^{*} r r}\left(P D^{* S R}\right)_{j}\right)$. 

observation) is $\mathrm{pk}=\operatorname{Logit}^{-1}\left(\alpha+\mu_{\mathrm{k}}^{3}\right)$. These values were used for plotting (Figs 2 and 3).

All continuous predictor variables were centred by subtracting their means prior to analysis, so that the main effect of the variable refers to its slope at the mean of all other variables.

Significance of the relationships between estimated proportional leaf damage and the fixed factors was determined using a parametric bootstrap approach. For each fixed factor, data was simulated under a simplified model without the fixed factor of interest. The full model was then fit to the simulated data and the $\mathrm{z}$ statistic was calculated. The observed $\mathrm{z}$ statistic from the full model was then compared to the distribution of $\mathrm{z}$ values obtained from 1000 such simulations, and a p value determined as the percent of simulated $\mathrm{z}$ values whose absolute value was greater than or equal to the absolute value of the observed z-value (Pinheiro \& Bates 2000).

\section{Results}

The average percentage of leaves damaged in this study was $53.6 \%$. The species of the plant had a large effect on the estimated proportional leaf damage, with estimated variance for the species random effect of 2.4 compared with 0.26 for the plot random effect and 0.82 for the observation random effect (equivalent in this model to residual variance). Leaf damage rates ranged from 5\% for the non-native highly defended Euphorbia cyparissias to close to $98 \%$ for the (also non-native) forage legume Medicago sativa (Fig. 2). Most of the common, native species such as Solidago canadensis, Asclepias syriaca and Symphyotrichum spp. had intermediate to high levels of herbivory (Fig. 2).

Sampling date was positively related to estimated proportional leaf damage but not significantly so ( $\mathrm{z}=1.05, \mathrm{p}=0.334$; Table 2$)$.

After accounting for species composition, I found a significant positive main effect of species richness $(\mathrm{z}=2.26, \mathrm{p}=0.042)$, and a near-significant negative main effect of phylogenetic diversity $(z=-0.19, p=0.055)$ on herbivory at the plot-level (Table 2, Fig. 3). There was also a significant negative interaction between phylogenetic diversity and species richness of plants ( $\mathrm{z}=-2.27, \mathrm{p}=0.043$; Table 2, Fig. 3), so that the positive effect of species richness on herbivory decreased with increasing phylogenetic diversity. This means that the plots with the highest estimated proportional leaf damage were plots with many species which tended to be closely related. Plots with few species and plots with more distantly related species tended to have lower herbivory (Fig. 3). Plots with the lowest phylogenetic 
271 ( 80\%) as plots with high phylogenetic diversity and low species richness ( 40\%, Fig 3).

\section{Discussion}

274 The results of this study show that phylogenetic diversity is a useful measure for 275 predicting the level of herbivory in plant communities. I have shown that community-level

276 herbivory tends to increase with plant species richness, consistent with some past studies, and 277 in contrast to other past studies (Table 1). On the other hand, I also showed, for the first time, 278 that high phylogenetic diversity of plant communities is associated with overall lowered 279 levels of herbivory. More importantly, there was an interaction between plant species richness and phylogenetic diversity, such that with increasing phylogenetic diversity, the positive effects of species richness on herbivory decrease. This means that the effects of plant species richness on herbivory is dependent on the level of phylogenetic diversity in the plant 283 community (and vice versa).

The effects of plant species richness on herbivory

The positive effect of plant species richness on herbivory (at the mean level of phylogenetic diversity) found here is the opposite of early ecological predictions (Elton 1958; Root 1973), but is not surprising given the frequency with which this pattern has been found in other systems (e.g. Mulder \& Huss-Danell 2001; Prieur-Richard et al. 2002; Scherber et al. 2006; Vehviläinen, Koricheva, \& Ruohomäki 2007; Lau et al. 2008; Schuldt et al. 2010; Plath et al. 2011; see Table 1). Theory predicting decreased levels of herbivory in speciose communities was based on the idea that specialist herbivores would be less likely to find and more likely to abandon diverse patches because abundance of their preferred hosts would necessarily be low in such communities (the Resource Concentration Hypothesis : Root 1973). However, this theory is dependent on the herbivore species' being monophagous.

296 Thus, in systems where monophages are rare or do not constitute the most damaging class of

297 herbivores, the Resource Concentration Hypothesis is unlikely to apply. Another theory for 298 why herbivore abundance and thus herbivory may be low in speciose plant communities is 299 the Enemies Hypothesis (Elton 1958; Root 1973), which suggests that predators will be more 300 abundant in diverse plant communities, and they will suppress herbivore populations.

301 However, several recent empirical tests of this hypothesis have shown little direct relationship

302 between plant species richness and predator abundance (Scherber et al. 2010a; Schuldt et al. 303 2011).

304 Theory for potential causes of a positive relationship between species richness and PeerJ reviewing PDF | (v2012:12:133:1:0:NEW 22 May 2013) 
herbivory, on the other hand, is less developed and less frequently cited. Some authors have suggested that this may be the result of nutritional advantages to generalist herbivores who have access to a variety of food resources in diverse patches (Bernays et al. 1994; Unsicker et al. 2008; Schuldt \& Baruffol 2010), which I refer to here as the Dietary Mixing Hypothesis. Other authors have suggested that spillover from preferred to less preferred host species could explain the effect, sometimes referred to as 'associational susceptibility' (White \& Whitham 2000).

On the other hand, the relationship between plant species richness and herbivory depends on the level of plant phylogenetic diversity you measure it at (the main effect is measured at the mean level of phylogenetic diversity - a natural place to do so). The implication of the significant interaction I found between plant species richness and plant phylogenetic diversity in explaining herbivore damage is that the phylogenetic diversity of the plots alters how species richness affects herbivory. I devote the next section to explaining how this interaction can be potentially explained as a natural outcome of a few simple principles.

The effects of plant phylogenetic diversity on herbivory (as mediated through plant species richness)

The likelihood of the Resource Concentration Hypothesis, the Dietary Mixing Hypothesis, or associational susceptibility being a factor may be related to the phylogenetic structure of the plant community, because many herbivore species, and especially insect herbivores, have phylogenetic structure in their diet - they feed on few or many species which tend to be closely related (Ehrlich \& Raven 1964; Janzen 1980; Ødegaard et al. 2005; Weiblen et al. 2006; Gossner et al. 2009; Futuyma \& Agrawal 2009). And so theory which is based on the dichotomy of specialist vs generalist herbivores is likely to be too simplistic to adequately describe real systems. Instead it is more useful to use three categories of herbivore which may inhabit a plant community: 1) True specialists or monophages - which feed on only a single plant species, 2) Phylogenetic specialists or cladophages - which feed on a group of related plant species, and 3) true generalists or polyphages - which feed on a group of plant species which has no pattern with respect to phylogeny at some relevant phylogenetic scale.

Though some authors use the term specialist and oligophage in a way consistent with the use of cladophage here - i.e. it is implied or explicitly stated that the author is using those 
339 also used in other ways. Oligophage literally means a species that feeds on a 'few' hosts

340 (oligo- is latin for ' $\mathrm{few}$ '), but does not specify whether these species are poly-, para-, or mono-phyletic. And the term 'specialist' usually needs qualification - e.g. a frugivore can be called a fruit specialist, and a cladophage can be called a phylogenetic specialist. It may then be tempting to conclude that I am introducing the term 'cladophage' because I am tired of typing out the much longer 'phylogenetic specialist' repeatedly. There is value to concision, but I hope the term cladophage will be useful for more than this.

The term cladophage can be more precisely defined as a species whose diet consists of other organisms that are more closely related than expected by chance. This means there is some vagueness to the term, as there are multiple ways to decide what is expected by chance (two methods for doing so can be found in Ødegaard et al. 2005, and Weiblen et al. 2006), which depend to some extent on what one is considering the potential diet pool. For example, the phylogenetic scale of the diet pool is important because almost any species can be considered a cladophage at some phylogenetic scale. For example, all insect herbivores are cladophages at the scale of the tree of life, because they only eat plants - a monophyletic clade. Another example is Milkweed Beetles (Tetraopes spp.), which only feed on Milkweed plants (Asclepias spp.), and so are cladophages when considering all possible plants. On the other hand, if you are only interested in Milkweed species as a potential diet pool, then Milkweed Beetles may not be considered cladophages because their diet could be random with respect to phylogeny within the Milkweed genera (Farrell and Mitter 1998). And so to properly define these categories, the phylogenetic scale of interest must also be defined. Practically speaking, for the study of herbivory, this will usually be based on the phylogenetic tree containing all the plant species present in the study, which will usually be the most appropriate for understanding local ecological dynamics (Cavender-Bares et al. 2009). This definition then potentially includes species whose diets are paraphyletic, as well as monophyletic. It should be noted that other terms contain some such relativity, including monophage. That is, a monophage is defined as a species that only eats one other organism, but it can be measured as what a species is observed to eat in its natural habitat, or as what a species potentially could eat, if given the opportunity. A monophage in a particular habitat may not be a monophage in another where some new host species becomes available. This concept of 'effective' specialization is important to understanding why phylogenetic diversity might affect the relationship between host species richness and herbivory. 
373

374

375

monophages nor polyphages should be affected by phylogenetic diversity of plants, at least directly - though nutritional effects are possible in generalists. On the other hand, cladophages are likely to respond to phylogenetic diversity of plants due to direct interactions with their host-plants (Dinnage et al. 2012). In a plant community with low phylogenetic diversity, if one host capable of supporting a particular cladophage is present, there is likely to be other suitable hosts as well (assuming the presence of at least moderate species richness). On the other hand, in plant communities with high phylogenetic diversity, if any hosts are suitable for a particular cladophage, it is likely to be the only one. This means that cladophages present in low phylogenetic diversity plant communities will be 'effective polyphages'; cladophages present in high phylogenetic diversity plant communities will be 'effective monophages'. Therefore, in plant communities with low phylogenetic diversity, cladophages are more likely to be able to take advantage of dietary mixing effects (as per the Dietary Mixing Hypothesis), and so species richness should have a positive effect. This is consistent with how phylogenetic diversity changed the effect of plant species richness on herbivory observed in this study - that is, the positive effect of species richness increased at low phylogenetic diversity, and decreased at high phylogenetic diversity (Fig. 3).

In plant communities with high phylogenetic diversity, cladophages will usually only be able to feed on one or a very few species, and so they may respond according to the Resource Concentration Hypothesis, that is, increasing the number of species in the plant community will make it more difficult for them to find their preferred host. Though in this study, the effect of species richness never became negative even at the highest level of phylogenetic diversity, it did become very nearly flat (Fig. 3). It is possible that the relationship would have become negative if there had been plots in this study with even higher phylogenetic diversity than observed.

There are several reasons why the relationship between plant species richness and herbivory may not become completely negative at the highest phylogenetic diversity of plants. For one, the effects of cladophages will be overlaid on the effects from monophages and polyphages. If the polyphage effect is more important in the system, then positive effects of plant species richness will likely predominate. Another possibility is that low species richness can sometimes have a negative effect on monophages, instead of the expected positive effect according to the Resource Concentration Hypothesis. These effects have been termed 'resource dilution effects' (Otway, Hector, \& Lawton 2005), and the commonness of their occurrence has yet to be established. 
407

408

409

410

411

412

413

414

415

416

417

418

419

420

421

422

423

424

425

426

427

428

429

430

431

432

433

434

435

436

437

438

439

440 reduced herbivory. It is not clear why functional diversity would decrease herbivory directly,

species richness, the overall main effect - measured at the mean level of plant species

richness - was negative, suggesting that in this system, there is an average decline in herbivory with phylogenetic diversity. Though no previous study has looked at the role of phylogenetic diversity per se on rates of herbivory in plant communities, my results are

consistent with the results of Jactel \& Brockerhoff (2007), who found in a meta-analysis that reductions in herbivory for focal trees grown in mixed stands instead of monoculture stands were stronger when the associated tree species in the mixed stand was taxonomically unrelated to the focal species.

\section{The role of cladophages in ecological systems}

The relative abundance of cladophages in this system is unknown, but it is likely that they occur regularly in most systems. It has been noted that the tendency for herbivores to feed on several closely related species is widespread (Ehrlich \& Raven 1964; Janzen 1980; Futuyma \& Agrawal 2009). If so, it is predicted that insect herbivore assemblages should be more similar in closely related plant hosts than in more distantly related ones. This pattern has been found in several recent studies in different systems (Ødegaard et al. 2005; Weiblen et al. 2006; Gossner et al. 2009). For example, in a tropical system, Weiblen et al. (2006) found that approximately half of the herbivore species they studied could be categorized as phylogenetic specialists.

The widespread existence of cladophages is also an assumption underlying the hypothesis that invasive species which are more distantly related to native species should experience higher levels of enemy release and thus lower levels of herbivory (Mitchell et al. 2006). This pattern, too, has been found in several recent studies (Dawson, Burslem, \& Hulme 2009; Hill \& Kotanen 2009; Ness, Rollinson, \& Whitney 2011). Native species have also been shown to experience lower herbivory when growing with neighbours which are distantly related (Yguel et al. 2011; Ness et al. 2011), further suggesting not only that cladophages are common, but that they exert important influence in ecological systems.

\section{Alternative explanations}

There are several alternative explanations for why phylogenetic diversity might indirectly affect herbivory. It has been suggested that phylogenetic diversity is a good proxy for unmeasured trait or functional diversity of a community (e.g. Cadotte et al. 2008; 
441 but it is possible that increased functional diversity could promote predator recruitment and 442 abundance, which in turn could suppress herbivores. Functional diversity could increase the 443 architectural complexity of a plot, allowing more hunting niches, nesting sites, and places to 444 hide and stalk for predators (Andow \& Prokrym 1990; Coll \& Botrell 1996; Beals 2006; 445 Woodcock et al. 2007). For example, Dinnage et al. (2012) found that in an experimental 446 prairie system, predator abundance increased strongly with phylogenetic diversity. However, 447 in the old field system at my study site, there was little variation in structural forms. Most 448 species grew with tall stalks, and leaves parallel to the ground along their entire height. There 449 were a few understory species (rosettes), a few vines, and a few tree or shrub saplings. Most 450 plots had all of these, regardless of phylogenetic diversity (Table S1, personal observation).

451 These growth forms occurred across the phylogenetic tree without any obvious patterns.

452 However, I cannot rule out this explanation without further information on the abundance of 453 predators. The effect may also have been the result of a combination of factors, that is, both 454 increased predator abundance and reduced diet breadth are jointly responsible for the 455 decrease in herbivory.

It is possible that a correlation between phylogenetic and functional diversity contributes to the patterns I observed in addition to the effects of cladophagy, but it does not offer a good explanation for the interaction between phylogenetic diversity and species richness, or the effect of species richness itself. This is because functional diversity is also expected to - and usually observed to - increase with species richness, and in fact this is often the explanation offered for why species richness affects various ecosystem functions

462 (Tilman 1997; Loreau et al. 2001; Hooper et al. 2005; Cardinale et al. 2006; Balvanera et al. 463 2006; Duffy et al. 2007; Cadotte et al. 2009; Fornara \& Tilman 2009; Cardinale 2011;

464 Connolly et al. 2011). Given this, we should expect to see a synergy between phylogenetic 465 diversity and species richness, rather than a negative interaction.

Though the observational nature of this study gives it the advantage of realism, it also 467 means I cannot completely rule out all confounding factors that may explain my results. If, 468 for example, there were abiotic conditions which influenced both species richness and 469 phylogenetic diversity, and also affected herbivory, and which varied sufficiently across my 470 sites, this could spuriously generate the observed correlations (Proches et al. 2009). Though 471 all the plots in this study came from a small geographic area and from a single habitat type, 472 and thus likely do not vary much in environmental conditions, it is possible that some soil 473 characteristics may have varied between the plots. Though environmental correlates of 474 species richness have attracted much interest in the past, especially at large spatial scales, PeerJ reviewing PDF | (v2012:12:133:1:0:NEW 22 May 2013) 
475 little is known about what environmental factors might influence phylogenetic diversity.

476 Since it is often supposed that phylogenetically closely related species will compete more

477 strongly, it is possible that plots with conditions that suppress competition amongst plants are

478 the only ones where many species which are closely related can coexist. If such conditions

479 also promoted high herbivory, then this could lead to high herbivory in plant communities

480 with high species richness and low phylogenetic diversity, as observed. To fully understand

481 the role of phylogenetic diversity in ecosystem function will require conducting large-scale

482 experiments where phylogenetic diversity is explicitly manipulated, but observational studies

483 in natural settings such as this will remain invaluable.

\section{Limitations of this study: Measuring the impact of herbivory}

This study shows that many plants may receive lower herbivore damage in

487 phylogenetically diverse communities. This result is similar to those of Yguel et al. (2011)

488 who found that oak trees that grew amongst distantly related trees experienced lower

489 herbivory. Yguel et al. (2011) suggested that this may produce a selective benefit that could

490 promote the evolution of a strategy to grow amongst distant relatives. This is an intriguing

491 possibility, but studies which only measure the magnitude of damage on plants cannot draw

492 this conclusion, unless they also measure the impact of damage on the plants. In order to

493 understand how selection might affect a plants' preference for its phylogenetic

494 neighbourhood, we need to know how the fitness of the plants are affected.

495 Damage is generally thought of as a negative impact on plant fitness, but many plants

496 are able to tolerate large amounts of damage without sustaining large reductions in fitness

497 (Rosenthal \& Kotanen 1994; Strauss \& Agrawal 1999). To understand fitness impacts of

498 herbivory generally requires measuring plant performance in the presence and absence of

499 herbivory. In Table 1, I show that although many studies that looked at the magnitude of

500 herbivory found that plant species richness increased herbivory, all but two studies that

501 looked at the impact of herbivory found a negative association with plant species richness,

502 such that speciose communities had a smaller difference in biomass between herbivore

503 exclusion and control treatments. This suggests that plant diversity may provide benefits in

504 terms of a plant's ability to tolerate herbivory, which more than makes up for any increases in

505 the actual amount of herbivore damage.

506 I therefore cannot conclude that any reduction in herbivory due to high phylogenetic

507 diversity necessarily results in an advantage to plants growing with their distant relatives.

508 However, the only way this would not be the case is if plants growing in low phylogenetic PeerJ reviewing PDF | (v2012:12:133:1:0:NEW 22 May 2013) 
diversity communities were more tolerant of damage than plants growing in high phylogenetic diversity communities, and this increase in tolerance fully compensated for the increase in herbivore damage. This seems unlikely, but cannot be ruled out without herbivore exclusion studies. It is possible, for example, that plants growing with distant relatives will tend to be in more marginal habitat, since abiotic niche requirements also may be similar for close relatives (Cavender-Bares et al. 2009). Plants in marginal habitat may be impacted by herbivory more.

\section{Implications for other studies}

As I show in Table 1, the results of previous studies are inconsistent about the relationship observed between herbivory and species richness. The interaction I observed between phylogenetic diversity and species richness in this study may offer an explanation. That is, the degree and even direction of the relationship between species richness and herbivory may depend on the difference in phylogenetic diversities of the communities that are compared. Though I observed such a relationship at a local scale, between individual plots, it may also apply on a larger scale. For example, it is possible that I may have observed an overall positive main effect of species richness in my study because there was generally a low amount of phylogenetic diversity in this system compared with other systems. Old fields tend to be dominated by species in the family Asteraceae, and the one I studied is no exception. Other systems where the question has been studied may draw from a larger pool of evolutionary history, where negative effects may perhaps be more likely.

Of course, the relative abundance and importance of monophages, polyphages, and cladophages present and active in the plant communities may also alter the observed effect of plant diversity. For example, simplified ecosystems such as agricultural systems - where we often see negative diversity-herbivory relationships (Andow 1991) - may be dominated by monophages, because monocultures on very large scales may discourage polyphages (or even many cladophages). Whereas polyphages need not be less common compared with monophages in monocultures that are imbedded in a more diverse landscape (as is the case for most biodiversity experiments), as long as the scale of the plots does not exceed the dispersal capability of the polyphages. In natural ecosystems, some systems may be more dominated by extinction-recolonization dynamics of both plants and herbivores, whereas others may be dominated by relatively stable populations of low-dispersal plant and

41 herbivores, which could also have major effects of Resource Concentration and Dietary PeerJ reviewing PDF | (v2012:12:133:1:0:NEW 22 May 2013) 
to play a strong role, in addition to the other factors.

Conclusion

Here I have shown that incorporating measures of phylogenetic diversity can improve our understanding of the role of plant diversity in promoting or suppressing herbivore damage. Phylogenetic diversity was negatively correlated with herbivory in an old field system, and determined the degree to which species richness influenced herbivory as well. If we consider a reduction in herbivore damage as a positive outcome at the community scale, as is often the case in agricultural ecosystems, then we may wish to prioritize the conservation and restoration of phylogenetic diversity, perhaps even at the expense of some species richness.

\section{Acknowledgements}

I am grateful to Anna K. Simonsen for logistical support. Ann P. Zimmerman provided assistance and granted permission for the use of KSR. Peter Abrams provided valuable feedback on an earlier draft of the manuscript.

\section{References}

Agrawal, A.A., Ackerly, D.D., Adler, F., Arnold, A.E., Cáceres, C., Doak, D.F., Post, E., Hudson, P.J., Maron, J., Mooney, K.A., Power, M., Schemske, D., Stachowicz, J., Strauss, S., Turner, M.G. \& Werner, E. (2007) Filling key gaps in population and community ecology. Frontiers in Ecology and the Environment, 5, 145-152.

Agrawal, A., Lau, J.A. \& Hamback, P.A. (2006) Community heterogeneity and the evolution of interactions between plants and insect herbivores. Quarterly Review of Biology, 81, 349-376.

Andow, D. (1991) Vegetational diversity and arthropod population response. Annual Review of Entomology, 36, 561-586.

Andow, D.A. \& Prokrym, D.R. (1990) Plant structural complexity and host-finding by a parasitoid. Oecologia, 82, 162-165.

Austin, M. P. (1999). A silent clash of paradigms: some inconsistencies in community ecology. Oikos, 86, 170-178.

Balvanera, P., Pfisterer, A.A.B., Buchmann, N., He, J.-S.J., Nakashizuka, T., Raffaelli, D. \& Schmid, B. (2006) Quantifying the evidence for biodiversity effects on ecosystem functioning and services. Ecology Letters, 9, 1146-56.

580 Beals, M.L. (2006) Understanding community structure: a data-driven multivariate approach. 
582

583

584

585

586

587

588

589

590

591

592

593

594

595

596

597

598

599

600

601

602

603

604

605

606

607

608

609

610

611

612

613

614

615

616

617

618

619

620

621

622

623

Bernays, E., Bright, K., Gonzalez, N. \& Angel, J. (1994) Dietary mixing in a generalist herbivore: tests of two hypotheses. Ecology, 1997-2006.

Cadotte, M.W., Cardinale, B.J. \& Oakley, T.H. (2008) Evolutionary history and the effect of biodiversity on plant productivity. Proceedings of the National Academy of Sciences of the United States of America, 105, 17012-7.

Cadotte, M.W., Cavender-Bares, J., Tilman, D. \& Oakley, T.H. (2009) Using phylogenetic, functional and trait diversity to understand patterns of plant community productivity. PloS one, 4, e5695.

Cadotte, M.W., Jonathan Davies, T., Regetz, J., Kembel, S.W., Cleland, E. \& Oakley, T.H. (2010) Phylogenetic diversity metrics for ecological communities: integrating species richness, abundance and evolutionary history. Ecology Letters, 13, 96-105.

Cardinale, B.J. (2011) Biodiversity improves water quality through niche partitioning. Nature, 472, 86-89.

Cardinale, B.J., Srivastava, D., Duffy, J., Wright, J.P., Downing, A.L., Sankaran, M. \& Jouseau, C. (2006) Effects of biodiversity on the functioning of trophic groups and ecosystems. Nature, 443, 989-992.

Cardinale, B.J., Wright, J.P., Cadotte, M.W., Carroll, I.T., Hector, A., Srivastava, D.S., Loreau, M. \& Weis, J.J. (2007) Impacts of plant diversity on biomass production increase through time because of species complementarity. Proceedings of the National Academy of Sciences of the United States of America, 104, 18123-8.

Cavender-Bares, J., Kozak, K.H., Fine, P.V.A. \& Kembel, S.W. (2009) The merging of community ecology and phylogenetic biology. Ecology Letters, 12, 693-715.

Coll, M. \& Botrell, D. (1996) Movement of an insect parasitoid in simple and diverse plant assemblages. Ecological Entomology, 21, 141-149.

Connolly, J., Cadotte, M.W., Brophy, C., Dooley, A., Finn, J., Kirwan, L., Roscher, C. \& Weigelt, A. (2011) Phylogenetically diverse grasslands are associated with pairwise interspecific processes that increase biomass. Ecology, 92, 1385-92.

Dawson, W., Burslem, D.F.R.P. \& Hulme, P.E. (2009) Herbivory is related to taxonomic isolation, but not to invasiveness of tropical alien plants. Diversity and Distributions, 15, 141-147.

Dinnage, R. (2009) Disturbance alters the phylogenetic composition and structure of plant communities in an old field system. PloS one, 4, e7071.

Dinnage, R., M.W. Cadotte, N.M. Haddad, G.M. Crutsinger, and D. Tilman. (2012) Diversity of plant evolutionary lineages promotes arthropod diversity. Ecology Letters, 15, 1308-1317.

Duffy, J.E., Cardinale, B.J., France, K.E., McIntyre, P.B., Thébault, E. \& Loreau, M. (2007) The functional role of biodiversity in ecosystems: incorporating trophic complexity. Ecology Letters, 10, 522-38.

Ehrlich, P.R. \& Raven, P.H. (1964) Butterflies and plants: a study in coevolution. Evolution, 18, 586-608.

Elton, C.S. (1958) The Ecology of Invasions by Animals and Plants. Methuen, London. 
665 666
(Coleoptera: Cerambycidae) and Asclepias (Asclepiadaceae) have co-evolved?. Biological Journal of the Linnean Society, 63, 553-577.

Flynn, D.F.B., Mirotchnick, N., Jain, M., Palmer, M.I. \& Naeem, S. (2011) Functional and phylogenetic diversity as predictors of biodiversity--ecosystem-function relationships. Ecology, 92, 1573-81.

Fornara, D.A. \& Tilman, D. (2009) Ecological mechanisms associated with the positive diversity-productivity relationship in an N-limited grassland. Ecology, 90, 408-418.

Futuyma, D.J. \& Agrawal, A.A. (2009) Macroevolution and the biological diversity of plants and herbivores. Proceedings of the National Academy of Sciences of the United States of America, 106, 18054-61.

Goodman, D. (1975). The theory of diversity-stability relationships in ecology. Quarterly Review of Biology, 50, 237-266.

Gossner, M.M., Chao, A., Bailey, R.I. \& Prinzing, A. (2009) Native fauna on exotic trees: phylogenetic conservatism and geographic contingency in two lineages of phytophages on two lineages of trees. American Naturalist, 173, 599-614.

Haddad, N.M., Tilman, D., Haarstad, J., Ritchie, M. \& Knops, J. (2001) Contrasting effects of plant richness and composition on insect communities: a field experiment. American Naturalist, 158, 17-35.

Hanley, M.E. (2004) Seedling herbivory and the influence of plant species richness in seedling neighbourhoods. Plant Ecology, 170, 35-41.

Helmus, M.R., Bland, T.J., Williams, C.K. \& Ives, A.R. (2007) Phylogenetic measures of biodiversity. American Naturalist, 169.

Hill, S.B. \& Kotanen, P.M. (2009) Evidence that phylogenetically novel non-indigenous plants experience less herbivory. Oecologia, 161, 581-90.

Hillebrand, H. \& Cardinale, B.J. (2004) Consumer effects decline with prey diversity. Ecology Letters, 7, 192-201.

Hooper, D., Chapin Iii, F., Ewel, J., Hector, A., Inchausti, P., Lavorel, S., Lawton, J., Lodge, D., Loreau, M., Naeem, S. \& others. (2005) Effects of biodiversity on ecosystem functioning: a consensus of current knowledge. Ecological Monographs, 75, 3-35.

Jactel, H. \& Brockerhoff, E.G. (2007) Tree diversity reduces herbivory by forest insects. Ecology Letters, 10, 835-48.

Janzen, D. (1980) Specificity of seed-attacking beetles in a Costa Rican deciduous forest. Journal of Ecology, 68, 929-952.

Koricheva, J., Mulder, C.P.H., Schmid, B., Joshi, J. \& Huss-Danell, K. (2000) Numerical responses of different trophic groups of invertebrates to manipulations of plant diversity in grasslands. Oecologia, 125, 271-282.

Lanta, V. (2007) Effect of slug grazing on biomass production of a plant community during a short-term biodiversity experiment. Acta Oecologica, 32, 145-151.

Lau, J. a, Strengbom, J., Stone, L.R., Reich, P.B. \& Tiffin, P. (2008) Direct and indirect effects of $\mathrm{CO} 2$, nitrogen, and community diversity on plant-enemy interactions. Ecology, 89, 226-36.

Loreau, M., Naeem, S., Inchausti, P., Bengtsson, J., Grime, J., Hector, A., Hooper, D., Huston, M., Raffaelli, D., Schmid, B. \& others. (2001) Biodiversity and ecosystem PeerJ reviewing PDF | (v2012:12:133:1:0:NEW 22 May 2013) 
668 669

670

671

672

673 674

675 676 677

678 679

680

681

682

683

684 685

686

687

688

689

690

691

692

693

694

695

696

697

698

699

700

701

702

703

704

705

706

707

708

709

McNaughton, S.J. (1985) Ecology of a Grazing Ecosystem: The Serengeti. Ecological Monographs, 55, 259.

Mitchell, C.E., Agrawal, A.A., Bever, J.D., Gilbert, G.S., Hufbauer, R.A., Klironomos, J.N., Maron, J.L., Morris, W.F., Parker, I.M., Power, A.G., Seabloom, E.W., Torchin, M.E. \& Vázquez, D.P. (2006) Biotic interactions and plant invasions. Ecology Letters, 9, 726-40.

Mulder, K. \& Huss-Danell, H. (2001) Insects affect relationships between plant species richness and ecosystem processes. Ecology Letters, 2, 237-246.

Narwani, A. \& Mazumder, A. (2010) Community composition and consumer identity determine the effect of resource species diversity on rates of consumption. Ecology, 91, 3441-7.

Ness, J.H., Rollinson, E.J. \& Whitney, K.D. (2011) Phylogenetic distance can predict susceptibility to attack by natural enemies. Oikos, 120, 1327-1334.

Nitschke, N., Ebeling, A., Rottstock, T., Scherber, C., Middelhoff, C., Creutzburg, S., Weigelt, A., Tscharntke, T., Fischer, M. \& Weisser, W.W. (2010) Time course of plant diversity effects on Centaurea jacea establishment and the role of competition and herbivory. Journal of Plant Ecology, 3, 109-121.

Ødegaard, F., Diserud, O.H. \& Østbye, K. (2005) The importance of plant relatedness for host utilization among phytophagous insects. Ecology Letters, 8, 612-617.

Otway, S., Hector, A. \& Lawton, J.H. (2005) Resource dilution effects on specialist insect herbivores in a grassland biodiversity experiment. Journal of Animal Ecology, 74, 234-240.

Pausas, J.G. \& Verdú, M. (2010) The Jungle of Methods for Evaluating Phenotypic and Phylogenetic Structure of Communities. BioScience, 60, 614-625.

Petermann, J.S., Müller, C.B., Weigelt, A., Weisser, W.W. \& Schmid, B. (2010) Effect of plant species loss on aphid-parasitoid communities. Journal of Animal Ecology, 79, 709-20.

Pfisterer, A.B., Diemer, M. \& Schmid, B. (2003) Dietary shift and lowered biomass gain of a generalist herbivore in species-poor experimental plant communities. Oecologia, 135, 234-241.

Pinheiro, J. \& Bates, D. (2000) Mixed-effects Models in S and S-PLUS. Springer.

Pio, D.V., Broennimann, O., Barraclough, T.G., Reeves, G., Rebelo, A.G., Thuiller, W., Guisan, A. \& Salamin, N. (2011) Spatial predictions of phylogenetic diversity in conservation decision making. Conservation Biology, 25, 1229-39.

Plath, M., Dorn, S., Riedel, J., Barrios, H. \& Mody, K. (2011) Associational resistance and associational susceptibility: specialist herbivores show contrasting responses to tree stand diversification. Oecologia, 1-11.

Prieur-Richard, A., Lavorel, S. \& Linhart, Y. (2002) Plant diversity, herbivory and resistance of a plant community to invasion in Mediterranean annual communities. Oecologia, 130, $96-104$.

Procheş, Ş., Forest, F., Veldtman, R., Chown, S. L., Cowling, R. M., Johnson, S. D., Richardson, D.M. \& Savolainen, V. (2009). Dissecting the plant-insect diversity relationship in the Cape. Molecular Phylogenetics and Evolution, 51, 94-99. 
R Development Core Team. (2010) R: A Language and Environment for Statistical Computing. $R$ Foundation for Statistical Computing.

Root, R.B. (1973) Organization of a plant-arthropod association in simple and diverse habitats: the fauna of collards (Brassica oleracea). Ecological Monographs, 43, 95-124.

Rosenthal, J.P. \& Kotanen, P.M. (1994) Terrestrial plant tolerance to herbivory. Trends in Ecology \& Evolution, 9, 145-8.

Schaffers, A.P., Raemakers, I.P., Sykora, K.V. \& ter Braak, C.J.F. (2008) Arthropod assemblages are best predicted by plant species composition. Ecology, 89, 782-794.

Scherber, C., Eisenhauer, N., Weisser, W.W., Schmid, B., Voigt, W., Fischer, M., Schulze, E.-D., Roscher, C., Weigelt, A., Allan, E., Bessler, H., Bonkowski, M., Buchmann, N., Buscot, F., Clement, L.W., Ebeling, A., Engels, C., Halle, S., Kertscher, I., Klein, A.-M., Koller, R., König, S., Kowalski, E., Kummer, V., Kuu, A., Lange, M., Lauterbach, D., Middelhoff, C., Migunova, V.D., Milcu, A., Müller, R., Partsch, S., Petermann, J.S., Renker, C., Rottstock, T., Sabais, A., Scheu, S., Schumacher, J., Temperton, V.M. \& Tscharntke, T. (2010a) Bottom-up effects of plant diversity on multitrophic interactions in a biodiversity experiment. Nature, 468, 553-6.

Scherber, C., Heimann, J., Köhler, G., Mitschunas, N. \& Weisser, W.W. (2010b) Functional identity versus species richness: herbivory resistance in plant communities. Oecologia, 163, 707-717-717.

Scherber, C., Mwangi, P.N., Temperton, V.M., Roscher, C., Schumacher, J., Schmid, B. \& Weisser, W.W. (2006) Effects of plant diversity on invertebrate herbivory in experimental grassland. Oecologia, 147, 489-500.

Schuldt, A. \& Baruffol, M. (2010) Tree diversity promotes insect herbivory in subtropical forests of south-east China. Journal of Ecology, 98, 917-926.

Schuldt, A., Both, S., Bruelheide, H., Härdtle, W., Schmid, B., Zhou, H. \& Assmann, T. (2011) Predator Diversity and Abundance Provide Little Support for the Enemies Hypothesis in Forests of High Tree Diversity (ed MS Boyce). PLoS ONE, 6, e22905.

Schweiger, O., Klotz, S., Durka, W. \& Kühn, I. (2008) A comparative test of phylogenetic diversity indices. Oecologia, 157, 485-95.

Siemann, E., Tilman, D., Haarstad, J. \& Ritchie, M. (1998) Experimental tests of the dependence of arthropod diversity on plant diversity. American Naturalist, 152, 738-750.

Sobek, S., Scherber, C., Steffan-Dewenter, I. \& Tscharntke, T. (2009) Sapling herbivory, invertebrate herbivores and predators across a natural tree diversity gradient in Germany's largest connected deciduous forest. Oecologia, 160, 279-88.

Stein, C., Unsicker, S.B., Kahmen, A., Wagner, M., Audorff, V., Auge, H., Prati, D. \& Weisser, W.W. (2010) Impact of invertebrate herbivory in grasslands depends on plant species diversity. Ecology, 91, 1639-1650.

Strauss, S.Y. \& Agrawal, A.A. (1999) The ecology and evolution of plant tolerance to herbivory. Trends in Ecology \& Evolution, 14, 179-185.

Tilman, D. (1997) The Influence of Functional Diversity and Composition on Ecosystem Processes. Science, 277, 1300-1302.

Unsicker, S.B., Baer, N., Kahmen, A., Wagner, M., Buchmann, N. \& Weisser, W.W. (2006) Invertebrate herbivory along a gradient of plant species diversity in extensively managed PeerJ reviewing PDF | (v2012:12:133:1:0:NEW 22 May 2013) 
755

756

757

758

759

760

761

Unsicker, S.B., Oswald, A., Köhler, G. \& Weisser, W.W. (2008) Complementarity effects through dietary mixing enhance the performance of a generalist insect herbivore. Oecologia, 156, 313-24.

Vamosi, S.M., Heard, S.B., Vamosi, J.C. \& Webb, C.O. (2009) Emerging patterns in the comparative analysis of phylogenetic community structure. Molecular Ecology, 18, 572-92.

Vehviläinen, H., Koricheva, J. \& Ruohomäki, K. (2007) Tree species diversity influences herbivore abundance and damage: meta-analysis of long-term forest experiments. Oecologia, 152, 287-98.

Wang, L., Wang, D., He, Z., Liu, G. \& Hodgkinson, K.C. (2010) Mechanisms linking plant species richness to foraging of a large herbivore. Journal of Applied Ecology, 47, no-no.

Weiblen, G., Webb, C., Novotny, V., Basset, Y. \& Miller, S. (2006) Phylogenetic dispersion of host use in a tropical insect herbivore community. Ecology, 87, 62-75.

White, J.A. \& Whitham, T.G. (2000) Associational susceptibility of cottonwood to a box elder herbivore. Ecology, 81, 1795-1803.

Wilsey, B.J. \& Polley, H.W. (2002) Reductions in grassland species evenness increase dicot seedling invasion and spittle bug infestation. Ecology Letters, 5, 676-684.

Woodcock, B.A., Potts, S.G., Westbury, D.B., Ramsay, A.J., Lambert, M., Harris, S.J. \& Brown, V.K. (2007) The importance of sward architectural complexity in structuring predatory and phytophagous invertebrate assemblages. Ecological Entomology, 32, 302-311.

Yguel, B., Bailey, R., Tosh, N.D., Vialatte, A., Vasseur, C., Vitrac, X., Jean, F. \& Prinzing, A. (2011) Phytophagy on phylogenetically isolated trees: why hosts should escape their relatives. Ecology Letters, 14, 1117-1124. 


\section{Table $\mathbf{1}_{\text {(on next page) }}$}

Literature review of previous studies on the role of plant diversity in promoting or supressing herbivory

Type refers to whether the species richness was manipulated (Experimental), natural species richness variation was taken advantage of (Observational), or the conclusion was based on estimates from previous literature (Meta-analysis). No study from the meta-analyses were repeated in this table. Consumer effect refers to whether the study estimated a measure of the amount of interaction between plants and consumers (Magnitude) - usually a damage measurement, or estimated the effect that interaction had on the plants' fitness (Impact) - usually by measuring biomass in the presence or absence of herbivory. A positive relationship means that the study found that the magnitude or impact of herbivory increased with increasing plant diversity, a negative relationship means the study found that herbivory decreased with plant diversity. None means the study found no relationship between herbivory and plant diversity 


\begin{tabular}{|c|c|c|c|c|c|c|}
\hline Study & Type & $\begin{array}{l}\text { Species } \\
\text { Richness } \\
\text { Range }\end{array}$ & Measured & $\begin{array}{l}\text { Measured On } \\
\text { effect }\end{array}$ & Consumer & Relationsh \\
\hline Lau et al. 2008 & Experimental & 1 vs. 16 & $\begin{array}{l}\text { Leaf damage } \\
\text { from generalists }\end{array}$ & 1 Legume sp & Magnitude & Positive \\
\hline $\begin{array}{l}\text { Mulder \& Huss- } \\
\text { Danell } 2001\end{array}$ & Experimental & $1,2,4,8,12$ & Leaf damage & Community & Magnitude & Positive \\
\hline Plath et al. 2011 & Experimental & 1 vs. 3 & Leaf damage & 1 Rosea tree & Magnitude & Positive \\
\hline $\begin{array}{l}\text { Prieur-Richard } \\
\text { et al. } 2002\end{array}$ & Experimental & $3,6,18$ & Leaf damage & 2 Conyza spp. & Magnitude & Positive \\
\hline $\begin{array}{l}\text { Scherber et al. } \\
2006\end{array}$ & Experimental & $\begin{array}{l}1,2,4,8,16 \\
\& 60\end{array}$ & Leaf damage & $\begin{array}{l}\text { All species + } 3 \\
\text { phytometer spp }\end{array}$ & Magnitude & Positive \\
\hline $\begin{array}{l}\text { Schuldt et al. } \\
2010\end{array}$ & Observational & $25-68$ & Leaf damage & 10 tree spp & Magnitude & Positive \\
\hline $\begin{array}{l}\text { Vehviläinen, } \\
\text { Koricheva \& } \\
\text { Ruohomäki } 2007\end{array}$ & Meta-analysis & 1 vs. Several & Leaf damage & $\begin{array}{l}2 \text { tree spp } \\
\text { (Oak \& Alder) }\end{array}$ & Magnitude & Positive \\
\hline Wang et al. 2010 & Observational & $1,2,4,6,8,11$ & $\begin{array}{l}\text { \# plants grazed } \\
\text { by sheep }\end{array}$ & Community & Magnitude & Positive \\
\hline $\begin{array}{l}\text { Hanley } 2004 \\
\text { relationship }\end{array}$ & Experimental & $3,6,12$ & $\begin{array}{l}\text { Leaf damage } \\
\text { by Mollusks }\end{array}$ & All spp & Magnitude & No \\
\hline $\begin{array}{l}\text { Sobek et al. } \\
\text { relationship } 2009\end{array}$ & Observational & $\begin{array}{l}\text { Natural range } \\
\text { across German } \\
\text { deciduous forest }\end{array}$ & $\begin{array}{l}\text { Leaf damage } \\
\text { by insects }\end{array}$ & 2 Maple spp & Magnitude & No \\
\hline $\begin{array}{l}\text { Yguel et al. } \\
\text { relationship } 2011\end{array}$ & Observational & $\begin{array}{l}\text { Natural range } \\
\text { across managed } \\
\text { French forest }\end{array}$ & Leaf damage & 1 Oak sp. & Magnitude & No \\
\hline $\begin{array}{l}\text { Jactel \& Brock- } \\
\text { erhoff } 2007\end{array}$ & Meta-analysis & 1 vs. Several & Leaf damage & $\begin{array}{l}\text { Many individual } \\
\text { spp. }\end{array}$ & Magnitude & Negative \\
\hline Lau et al. 2008 & Experimental & 1 vs. 16 & $\begin{array}{l}\text { Leaf damage } \\
\text { from specialists }\end{array}$ & 1 Legume sp & Magnitude & Negative \\
\hline $\begin{array}{l}\text { Massey et al. } \\
2006\end{array}$ & Experimental & 1 vs. 5 & Leaf damage & 1 Shorea sp & Magnitude & Negative \\
\hline $\begin{array}{l}\text { McNaughton } \\
1985\end{array}$ & Observational & $\begin{array}{l}\text { Natural range } \\
\text { across Serengeti }\end{array}$ & $\begin{array}{l}\% \text { Biomass } \\
\text { consumed }\end{array}$ & Community & Magnitude & Negative \\
\hline $\begin{array}{l}\text { Petermann et } \\
\text { al. } 2010\end{array}$ & Experimental & $1,2,3,4,6,9$ & $\begin{array}{l}\text { Infestation by } \\
\text { aphids }\end{array}$ & Community & Magnitude & Negative \\
\hline $\begin{array}{l}\text { Sobek et al. } \\
2009\end{array}$ & Observational & $\begin{array}{l}\text { Natural range } \\
\text { across German } \\
\text { deciduous forest }\end{array}$ & $\begin{array}{l}\text { Leaf damage } \\
\text { by insects }\end{array}$ & 1 Beech sp & Magnitude & Negative \\
\hline
\end{tabular}




\begin{tabular}{|c|c|c|c|c|c|c|}
\hline $\begin{array}{l}\text { Unsicker et al. } \\
2006\end{array}$ & Observational & $18-45$ & Leaf damage & $\begin{array}{l}\text { Many individual } \\
\text { spp. }\end{array}$ & Magnitude & Negative \\
\hline $\begin{array}{l}\text { Vehviläinen, } \\
\text { Koricheva \& } \\
\text { Ruohomäki } 2007\end{array}$ & Meta-analysis & 1 vs. Several & $\begin{array}{l}\text { Leaf damage } \\
\text { by insects }\end{array}$ & 1 Birch sp & Magnitude & Negative \\
\hline $\begin{array}{l}\text { Wilsey \& Polley } \\
2002\end{array}$ & Experimental & $\begin{array}{l}1-4 \\
\text { (manipulated } \\
\text { Evenness) }\end{array}$ & $\begin{array}{l}\text { Infestation by } \\
\text { spittlebugs }\end{array}$ & $\begin{array}{l}\text { Solidago } \\
\text { canadensis }\end{array}$ & Magnitude & Negative \\
\hline $\begin{array}{l}\text { Mulder \& Huss- } \\
\text { Danell } 2001\end{array}$ & Experimental & $1,2,4,8,12$ & $\begin{array}{l}\text { Reduction of } \\
\text { biomass in } \\
\text { insecticide plots }\end{array}$ & Community & Impact & Positive \\
\hline $\begin{array}{l}\text { Scherber et al. } \\
\text { relationship } \\
2010\end{array}$ & Experimental & $1,2,4,8,16,60$ & $\begin{array}{l}\% \text { reduction of } \\
\text { biomass in insect } \\
\text { exclusions }\end{array}$ & Community & Impact & No \\
\hline $\begin{array}{l}\text { Hillebrand \& } \\
\text { Cardinale } 2004\end{array}$ & Meta-analysis & $1-60$ & $\begin{array}{l}\text { Absolute and \% } \\
\text { reduction of bio- } \\
\text { mass in grazer } \\
\text { exclusion }\end{array}$ & $\begin{array}{l}\text { Community of } \\
\text { phytoplankton }\end{array}$ & Impact & Negative \\
\hline Lanta 2007 & Experimental & $1,2,4,6$ & $\begin{array}{l}\text { Reduction of } \\
\text { biomass in Mol- } \\
\text { lusk exclusions }\end{array}$ & Community & Impact & Negative \\
\hline $\begin{array}{l}\text { Narwani \& } \\
\text { Mazumder } 2010\end{array}$ & Experimental & 1 vs. 4 & $\begin{array}{l}\text { Biomass } \\
\text { consumed }\end{array}$ & $\begin{array}{l}\text { Community of } \\
\text { phytoplankton }\end{array}$ & Impact & Negative \\
\hline $\begin{array}{l}\text { Pfisterer, } \\
\text { Negative }\end{array}$ & Experimental & $1,2,4, \varepsilon$ & $\%$ reduct & tion of Commu & Impact & \\
\hline $\begin{array}{l}\text { Diemer \& } \\
\text { Schmid } 2003\end{array}$ & & & $\begin{array}{l}\text { biomass in insect } \\
\text { exclusion }\end{array}$ & & & \\
\hline Stein et al. 2010 & Observational & $15-37$ & $\begin{array}{l}\% \text { reduction of } \\
\text { biomass in insect } \\
\text { exclusions }\end{array}$ & Community & Impact & Negative \\
\hline
\end{tabular}




\section{Figure 1}

Phylogenetic tree with branch lengths representing all species in this study

Species highlighted in grey are species for which herbivore damage measurements were taken. Branch lengths represent divergence times. Methods for generating the tree can be found in Dinnage (2009).

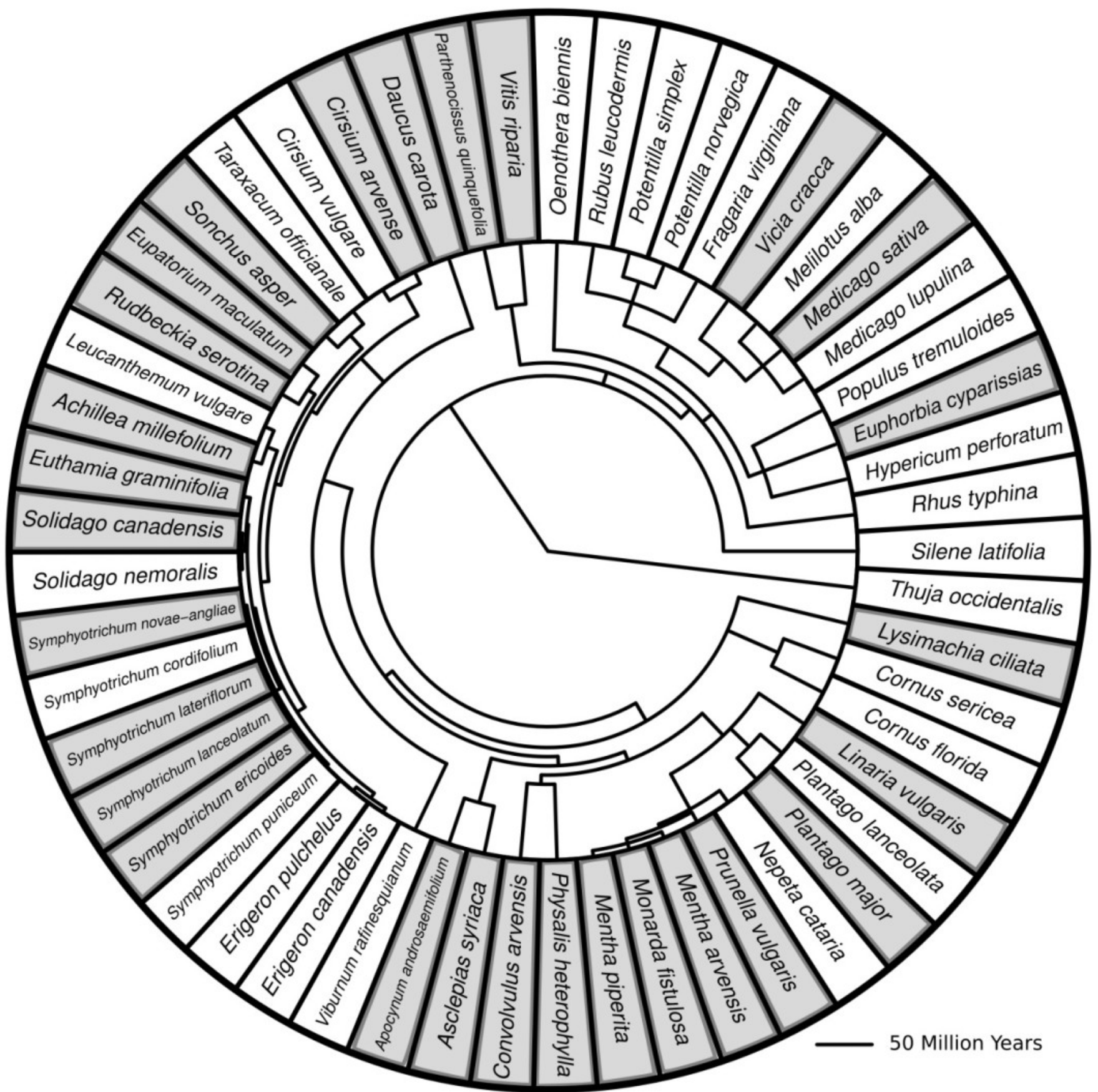




\section{Figure 2}

Species-level herbivory of the 27 species for which herbivore damage measurements were taken

On the left is the phylogenetic relationships of the species with branch length representing time since divergence. On the right is a barchart whose bars represent the best linear unbiased predictors (BLUPs) or conditional modes of the estimated proportional leaf damage for each species. Error bars are based on the conditional variance-covariance matrix generated by the model fitting procedure (lmer function in the lme4 package for $\mathrm{R}$ ) and are conditional mode $+/-1$ conditional standard deviation.

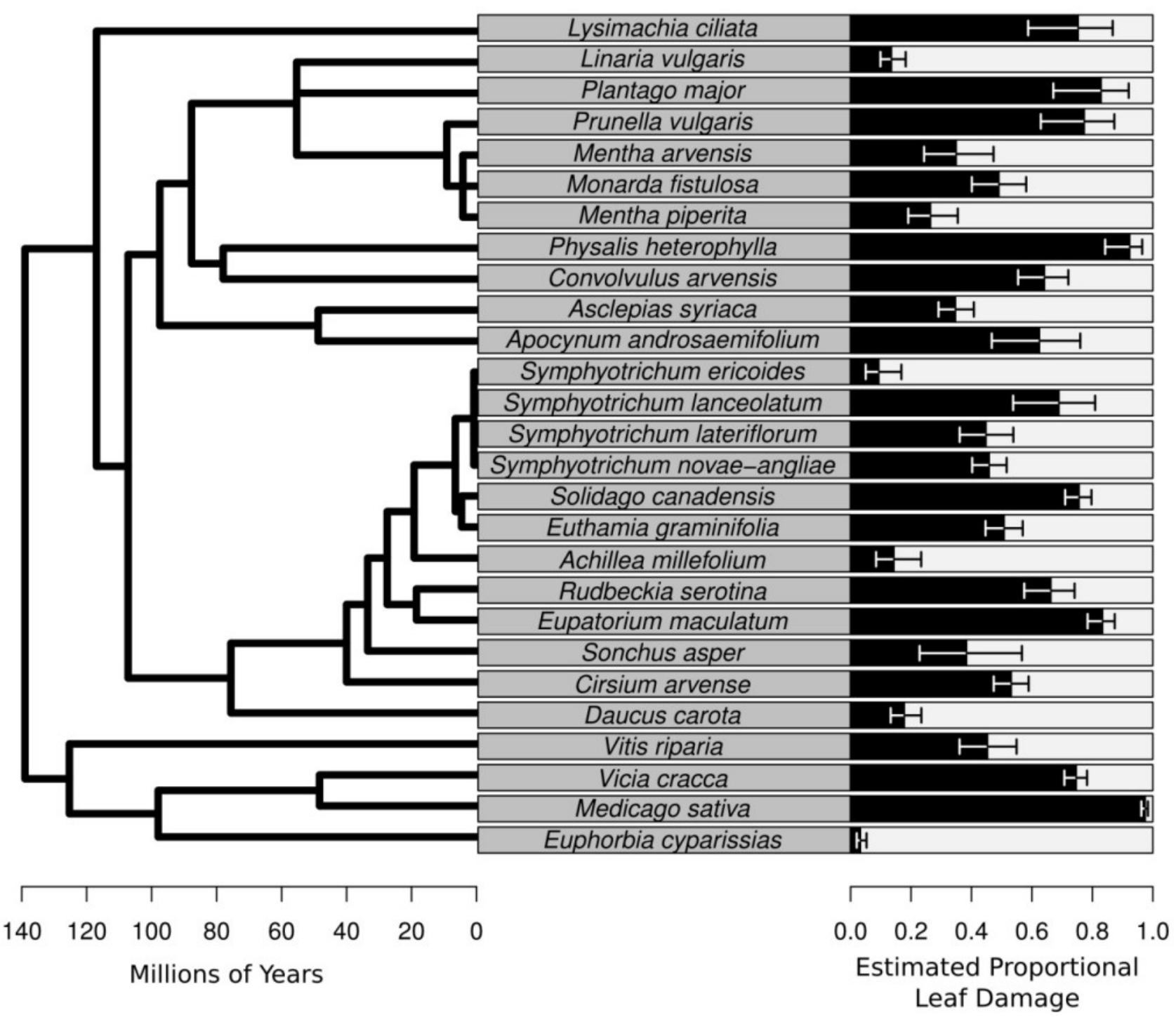




\section{Table $2_{\text {(on next page) }}$}

Statistics for the fixed effects

Statistics for the fixed effects in a generalized linear mixed model (GLMM) with binomial family and logit link. $\operatorname{Pr}\left(|z|_{\text {obs }}<|z|_{\text {sim }}\right)$ is the p-value generated from a parametric bootstrap on the $\mathrm{z}$ values. ${ }^{*} \mathrm{z}$ value is significant at the alpha $=0.05$ level. 


$\begin{array}{llccc}\text { Parameter } & \text { Name of Factor } & \text { Estimate } & \mathbf{z} \text { value } & \operatorname{Pr}\left(|\mathbf{z}|_{\text {obs }}<|\mathbf{z}|_{\text {sim }}\right) \\ \alpha & \text { Intercept } & 0.15 & & \\ \beta_{d a t e} & \text { Sampling Date } & 0.10 & 1.05 & 0.334 \\ \beta_{s r} & \text { Plant Species Richness } & 0.23 & 2.26 & 0.042^{*} \\ \beta_{p d} & \text { Plant Phylogenetic Diversity (PSE) } & -0.19 & -2.10 & 0.055 \\ \beta_{s r^{*} p d} & \text { Plant Diversity Interaction } & -0.28 & -2.27 & 0.043^{*}\end{array}$




\section{Figure 3}

Two figures showing the relationship between estimated proportional leaf damage and plot-level plant species richness and phylogenetic diversity.

a) Points represent best linear unbiased predictors (BLUPs) or conditional modes of plots. The size of the points is proportional to the species richness of the plot so that large points are speciose communities. Error bars are based on the conditional variance-covariance matrix generated by the model fitting procedure (lmer function in the lme4 package for $\mathrm{R}$ ) and are conditional mode $+/-1$ conditional standard deviation. Fitted lines are back-transformed predicted values from the full generalized linear mixed model, for four different pre-set values of species richness $(3,6,12, \& 17)$ representing the full range of species richnesses in this study. b) A heatmap which shows the back-transformed fitted surface of the full generalized linear mixed model. Points are the plot BLUPs, their colour represents their value as per the legend. Points that are darker than the surrounding colour fall below the predicted surface; points which are lighter fall above it.
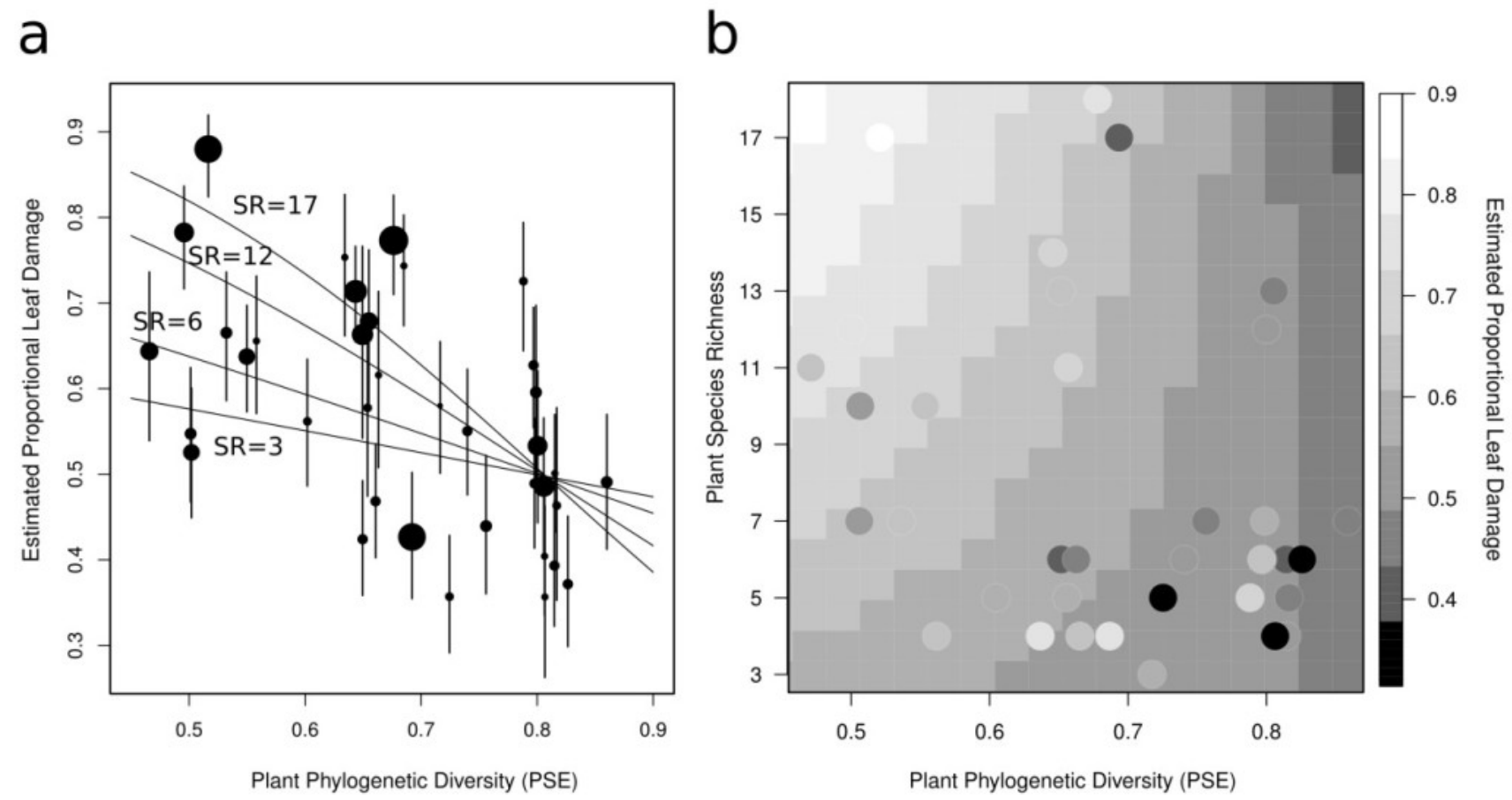